\title{
Justification of cooficients reqiered for correction of rates of detail needs for machine maintenance and repair
}

\author{
Alexey Shisteev ${ }^{*}, 1$, Galina Buraeva $^{1}$, Petr Ilyin ${ }^{1}$, Victoriya Kovalivnich $^{1}$, and Sergey \\ Agafov ${ }^{1}$ \\ ${ }^{1}$ Irkutsk State Agricultural University named after A.A. Ezhevsky, 664038, 1/1, Molodezhnyy, \\ Irkutsk Oblast, Russia
}

\begin{abstract}
When solving the problems of increasing the reliability of automotive and tractor equipment during the regular repair period, a problem of adjusting the norms of the need for spare parts appears. The lack of recommendations for their determination, depending on the operating conditions, determines the need to deepen the analysis, development and refinement of techniques in order to clarify and adjust the normalizing factors.
\end{abstract}

\section{Introduction}

In this article the aim of the study is - to substantiate theoretically the possibility of adjusting the norms of the need for parts for machine maintenance and repair in Irkutsk region conditions. The difference between the wearout and tear of machines and their elements during the operation of motor and tractor equipment in moderate and severe climatic conditions was taken as a basis. The instability of external and internal disturbing factors, their probable nature, widely varies the parameters of parts condition. The studies were carried out at agricultural enterprises of Irkutsk region, located in areas with moderate - cold (southern areas of the region), cold (Zhigalovsky, Bratsk, Ust-Ilimsky, Kirensky regions) and very cold (Mamsko-Chunsky, Bodaibinsky, Katangsky regions) climate. The smallest picking size was 10 machines of the same brand (model) in some farms, in some farms, and it was 30 machines and more in other farms. Observations were carried out until the objects failure. The capacity of picking was more than 180 values of operating time of various replacement parts [1-2].

In Irkutsk region the Katangsky area refers to northern territories, at the same time the Bodaibinsky, Bratsky, Kazachinsko-Lensky, Kirensky, Mamsko-Chuisky, Nizhneilimsky, Ust-Ilimsky, Ust-Kutsky areas, as well as the cities Bodaibo, Ust- Ilimsk, Ust-Kut, Bratsk apply to the Far North territory. The caltivated area in these territories is about 40 thousand hectares (5.8\% from the regional indicator). The total caltivated area of grain crops in these territories is 19485 hectares $(4.5 \%)$, potatoes - 7567 hectares $(19.6 \%)$ and vegetables - 988

\footnotetext{
${ }^{*}$ Corresponding author: drive-er@yandex.ru
} 
hectares (17\%). In despite of recommendations given by the manufacturer or machine test stations [6] very often zonal operating conditions of equipment require corrections to the consumption rates of operating materials. Each machine has a number of elements that are exposed to climatic, soil, load and other zonal operational factors and due to this the parts wear out and become less durable [1]. Changes in the resource parameters of parts under the influence of the above mentioned factors, increase the duration of machine downtime for repair and maintenance and increase the related to these factors costs $[5,9]$ accordingly. In this regard, it becomes necessary to correct the norms of rates of their consumption in the form of a system of correction coefficients depending on climatic conditions $[2,6]$. The aim of the study is- to substantiate theoretically the possibility of adjusting the norms of the need for parts for machine maintenance and repair in Irkutsk region conditions. The goal of this research is to substantiate theoretically the correction coefficients for the norms of the need for parts during maintenance and repair of automotive vehicles.

Solution technique. It is known that there is an reverse proportional dependence between the rate of wearout and the resource of parts

$$
\frac{U_{1}}{U_{2}}=\frac{L_{2}}{L_{1}}
$$

where $U_{1}$ - the intensity of wear rate of machine parts at an ambient temperature $T_{1}$;

$U_{2}$ - the intensity of wear rate of machine parts at ambient temperature $T_{2}$;

$L_{1}, L_{2}$ - part resources at temperatures $T_{1}, T_{2}$.

If the service life of the unit is equal to $\mathrm{R}$, then the required number of parts for this period at ambient temperatures $\mathrm{T}_{1}, \mathrm{~T}_{2}$ will be

$$
\frac{R}{L_{1}}=n_{1} ; \quad \frac{R}{L_{2}}=n_{2}
$$

their ratio equal

$$
\frac{L_{1}}{L_{2}}=\frac{n_{1}}{n_{2}}=k
$$

Expression (3) suggests that in order to obtain the coefficients for correcting the norms of the need for parts for maintenance and repair of machines in different climatic zones, it is enough to compare their resources [4].

For technical service of engines the value of the coefficient $k$ is the ratio of three components.

$$
k_{d 0}=k_{d 1} \cdot k_{d 2} \cdot k_{d 3}
$$

where $k_{d 1}$ - is the generalized coefficient for correcting the norms of the need for parts for engine repair;

$k_{d 2}$ - coefficient taking into account wearout due to the intensification of the working process in the engine under the influence of incoming cold air;

$k_{d 3}$ - coefficient characterizing engine wear from an increase in specific loads on units and interfaces when the machine overcomes a denser air environment;

$$
k_{d 1}=\frac{T_{2}}{T_{2}-\Delta T}
$$

To determine the coefficient $\mathrm{k}_{d 2}$, it is taken into account that when the load changes, the durability of parts changes as 


$$
L=\frac{A_{k}}{p^{m}}
$$

where $L-$ is the resource of the part;

$A k$ - is a coefficient that determines the construction reserve;

$p$ - is the load on the construction;

$m-$ is an indicator characterizing the type of load that predetermines the wear of parts.

For various operating conditions we will have:

$$
\frac{L_{1}}{L_{2}}=\frac{A_{k 1} \cdot p_{2}^{m}}{A_{k 2} \cdot p_{1}^{m}}
$$

where $L_{1}, L_{2}$ - resources of parts of vehicle operating temperatures $T_{1}$ and $T_{2}$.

Since climatic reliability is built-in into the design of the car, the coefficient that determines the exposure of the car to the environment influences for one and the same type of parts and assemblies will be constant. This implies

$$
\frac{L_{1}}{L_{2}}=\frac{p_{2}^{m}}{p_{1}^{m}}
$$

In the above mentioned case the role of the load plays $N_{w}$. Taking this into account, we represent expression (8) as the following

$$
\frac{L_{1}}{L_{2}}=\left(\frac{N_{w}}{N_{w 1}}\right)^{m}
$$

or

$$
\frac{L_{1}}{L_{2}}=\left(\frac{T_{1}}{T_{2}}\right)^{m}
$$

For the engine, wearout as a function of load has a directly proportional ratio, that is why

$$
k_{d 2}=\frac{T_{1}}{T_{2}}
$$

The theoretical determination of the coefficient $\mathrm{k}_{d 3}$, is of considerable difficulty due to multiplicity of factors affecting wear of details during unsteady thermal conditions of engine, including the start-up and warm-up cycles. In this connection, it is easier to determine it experimentally [3].

The value of the generalized correction coefficient of norms for the consumption rates of transmission parts may be represented as a product of three factors

$$
k_{T 0}=k_{T 1} \cdot k_{T 2} \cdot k_{T 3}
$$

where $k_{T 1}$ - is a coefficient that takes into account wear when the temperature of the oil in the transmission units changes during the operation of the machine relative to its average value;

$k_{T 2}$ - is a coefficient that takes into account wear from an increase of specific load in the interfaces when overcoming a denser air environment;

$k_{T 3}-$ is a coefficient taking into account the wear of the transmission during its start-up and warm-up.

Considering the results of studies [5], the wear that occurs when the oil temperature in the transmission units changes from 0 to plus $90{ }^{\circ} \mathrm{C}$ can be neglected. Therefore, we take the value of the coefficient $k_{T I}$ equal to one [5]. 
The value of the coefficient $k_{T 2}$ in accordance with expression (10) can be represented as:

$$
k_{T 2}=\left(\frac{T_{1}}{T_{2}}\right)^{m}
$$

For gear drives, shafts, bearings, which are characterized by a high contact load, the exponent " $m$ " is usually taken equal to 3 .

The theoretical determination of the coefficient $k_{T 3}$, as in the previous case, is extremely difficult and that is why it is advisable to determine them statistically.

\section{Results and its discussion}

From the total wear of the machine taken as $100 \%$, the average share of wear of engine parts due to the influence of cold air on the working process was approximately $22.5 \%$, the share of wear of parts from the removal of additional power to overcome a denser air environment by the car was about $21 \%$; wear corresponding to start-up - warm-up cycles was $12.5 \%$. The share of wearout corresponding to other factors was $44 \%$ (Figure 1 ).

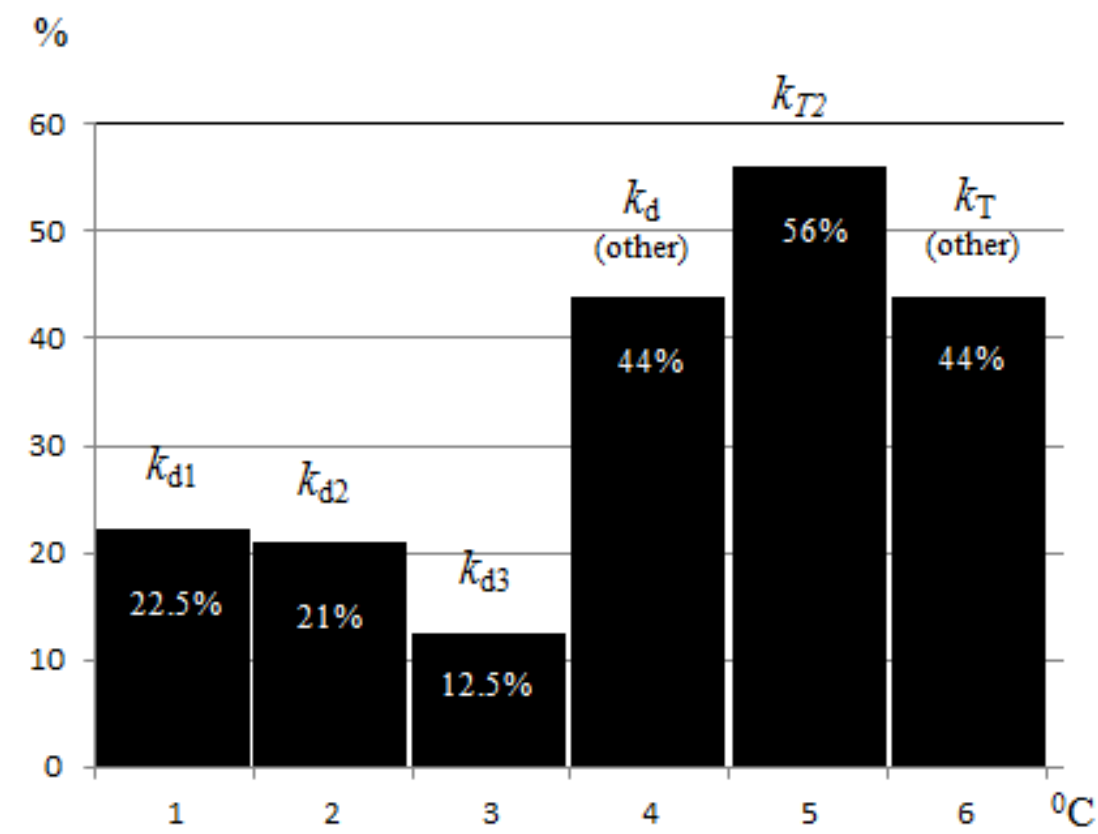

Fig. 1. The proportion of wear of engine and transmission parts in the machine

The reason for such a situation lies in the lack of covered (heated) parking lots in regions with cold climate, both in the main bases of the car and at intermediate points along the way [8]. Car drivers are forced not to turn off their car engines during the whole cold season, and this leads a significant loss of motor resources [7]. Also the car drivers are forced to suppress engines for a period of time while the coolant cools down to a temperature of $20-0{ }^{\circ} \mathrm{C}$. The last action increases the number of starts, which also reduces motor resources.

A similar situation has developed with respect to transmission parts (Figure 2). First of all, starting the car from a place after a long parking leads to increased wear of transmission 
parts [5], especially at temperatures below the pour point of the gear oil. In this case, power train gears cut a hole in the frozen oil and operate for a relatively long time (15-20 minutes) in unfavorable lubrication conditions - until the transmission warms up and the oil temperature in its units rises to a value of plus $20-30{ }^{\circ} \mathrm{C}$. Warming up to this temperature ensures its reliable coming into the friction zone and the formation of a strong oil film on the contacting surfaces.

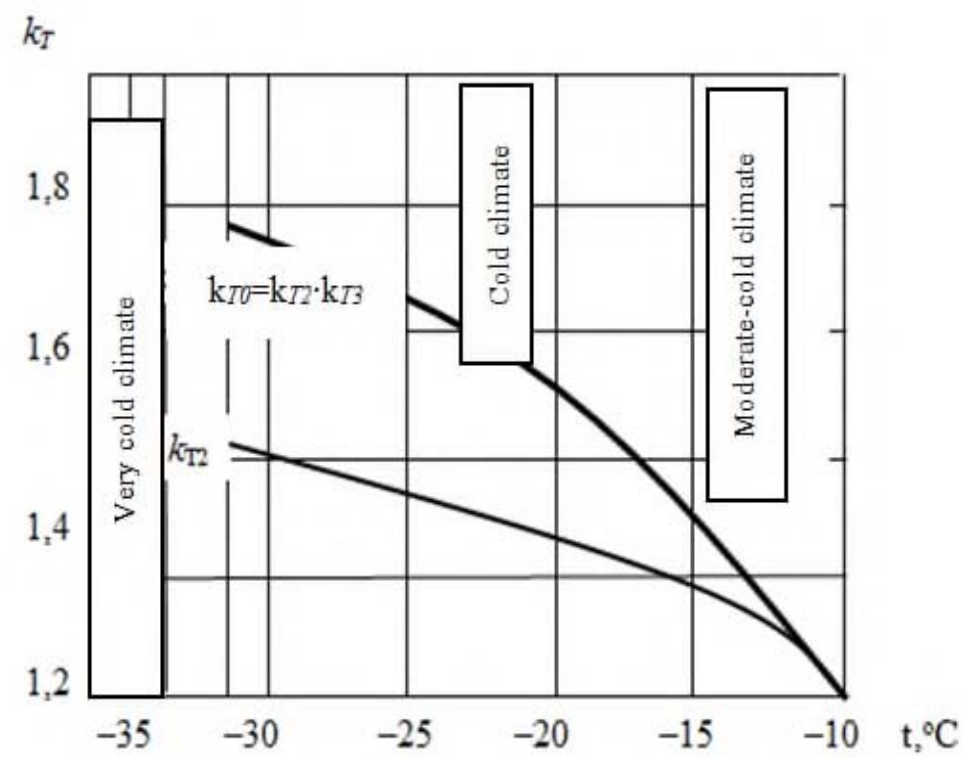

Fig. 2. Change of the generalized coefficient of correction of norms of consumption rates of transmission parts and its components in areas of operation.

Analytical and experimental studies have shown the expediency of a strategy for the zonal formation of spare parts for technical and repair maintenance, in which an amendment towards an increase of the current standards applies to parts exposed to severe climatic conditions.

The value of the calculated correction coefficients for the consumption rates is largely correlated with the experimental values. Being developed system for correction of norms should meet the existing resource provision. This condition was complied.

Table 1. Coefficients for correction norms of rates of consumption of spare parts for maintenance and repair of engine and transmission for KamAZ vehicles

\begin{tabular}{|l|c|c|c|c|c|c|c|c|c|}
\hline \multirow{2}{*}{ Group name } & \multicolumn{9}{|c|}{ Group coefficients } \\
\cline { 2 - 10 } & \multicolumn{10}{|c|}{ Moderate-cold climate } & \multicolumn{3}{c|}{ Cold climate } & \multicolumn{3}{c|}{ Very cold climate } \\
\cline { 2 - 10 } & $\overline{\boldsymbol{k}}_{\boldsymbol{i}}$ & $\boldsymbol{k}_{\text {imin }}$ & $\boldsymbol{k}_{\text {imax }}$ & $\overline{\boldsymbol{k}}_{\boldsymbol{i}}$ & $\boldsymbol{k}_{\text {imin }}$ & $\boldsymbol{k}_{\text {imax }}$ & $\overline{\boldsymbol{k}}_{\boldsymbol{i}}$ & $\boldsymbol{k}_{\text {imin }}$ & $\boldsymbol{k}_{\text {imax }}$ \\
\hline 1 & 4 & 5 & 6 & 7 & 8 & 9 & 10 & 11 & 12 \\
\hline $\begin{array}{l}\text { Mechanical parts of the } \\
\text { engine and } \\
\text { transmission, the } \\
\text { specific load on which } \\
\text { increases with } \\
\text { decreasing ambient } \\
\text { temperature }\end{array}$ & 1,2 & 1,1 & 1,27 & 1,4 & 1,26 & 1,48 & 1,72 & 1,51 & 1,83 \\
\hline
\end{tabular}


Table 2. Correction coefficients for consumption rates of spare parts for the needs of repair and maintenance in the areas of operation

\begin{tabular}{|c|c|c|}
\hline \multirow{2}{*}{ Climatic region } & \multicolumn{2}{|c|}{ Correction coefficients } \\
\cline { 2 - 3 } & KamAZ & MTZ - 1221 \\
\hline Moderate - cold & 1,1 & 1 \\
\hline Cold & 1,24 & 1,15 \\
\hline Very cold & 1,45 & 1,35 \\
\hline
\end{tabular}

In the case when the zone supervised by the repair company covers several climatic regions, it is proposed to determine the average values of the correction coefficients for the total cost and detailed norms of spare parts.

\section{Conclusion}

Studies have shown that under the influence of a cold climate in parts made of metal alloys cold brittleness increases, reliability is significantly reduces and wearout of working surfaces increases. The share of wear of parts of automotive vehicles exposed to low temperatures is more than $40 \%$. The value of the calculated correction coefficients for the consumption rates of the mechanical parts of the engine and transmission in a very cold climate zone is on average $69 \%$ higher than in a moderately cold climate zone when the specific load on them increases with a decrease of the ambient air temperature. This indicates that it is necessary to improve the standards for the consumption of repair resources for the needs of technical service, as well as to improve the production and technical base of enterprises in zonal conditions the specific load on which increases with a decrease in the ambient air temperature.

\section{References}

1. M. Buraev, A. Shisteev, A. Zhabin, A. Anosova, P. Ilyin, To clarify the standards of spare parts for technical service of autotractors in zone conditions. E3S Web of Conferences, 175, 05001 (2020)

2. T. Bodyakina, P. Boloev, M. Buraev, A. Shisteev, Diagnostics of hydraulic density of plunger couple of tractor diesel, E3S Web of Conferences, 175, 05035 (2020)

3. A. Bacchetti, N. Saccani, Spare parts classification and demand forecasting for stock control: Investigating the gap between research and practice, Omega, 40, 722-737 (2012)

4. P. Sharma, A simulation based optimization approach for spare parts forecasting and selective maintenance. Reliability Engineering and System Safety, 168, 274-289 (2017)

5. K. Antosz, Classification of spare parts as the element of a proper realization of the machine maintenance process and logistics - case study, IFAC-Papers On Line 49-12 1389-1393 (2016)

6. D. Lengu, Spare parts management: Linking distributional assumptions to demand classification. European Journal of Operational Research, 235, 624-635 (2014)

7. Y. Ding, Model predictive control and its application in agriculture: A review, Computers and Electronics in Agriculture, 151, 104-117 (2018) 
8. Y. Hu, Y. Liu, Z. Wang, J. Wen, J. Li, J. Lu, A two-stage dynamic capacity planning approach for agricultural machinery maintenance service with demand uncertainty. Biosystems engineering, 190, 201-217 (2020)

9. E. V. Eltoshkina, P. I. Ilyin, N. I. Ovchinnikova, O. A. Svirbutovich, D. M. Rozhkov, Evaluation of the limit properties of a solid body system, IOP conference series: materials science and engineering. Irkutsk National Research Technical University, 012023 (2019)

10. A. Osmakova, Recent biotechnology developments and trends in the Russian Federation. New Biotechnology, 40, 76-81 (2018)

11. S. Zhu, Spare parts inventory control based on maintenance planning. Reliability engineering and System Safety, 193, 106600 (2020)

12. S. Van der Auweraer, R. Boute, Forecasting spare part demand using service maintenance information. International Journal of Production Economics, 213, 138149 (2019)

13. S. A. Al-Suhaibani, M. F. Wahby, Farm tractors breakdown classification Journal of the Saudi. Society of Agricultural Sciences, 16, 294-298 (2017)

14. M. Buraev, P. Ilyin, S. Ilyin, A. Shisteev, A. Anosova, The calculation program of the technical service enterprise of transport-technological machines in agriculture. IOP Conference Series: Materials Science and Engineering, 632(1), (2019) doi: 10.1088/1757-899X/632/1/012019

15. Y. M. Krakovsky, A. N. Luzgin, Y. M. Ivanyo, Cyberattack intensity forecasting on informatization objects of critical infrastructures. IOP Conference Series: Materials Science and Engineering, 481(1), 012003 (2019) 